Check for updates

Cite this: RSC Adv., 2021, 11, 37540

Received 15th October 2021

Accepted 9th November 2021

DOI: $10.1039 / \mathrm{d} 1 \mathrm{ra} 07650 \mathrm{~g}$

rsc.li/rsc-advances

\section{Acetonitrile and benzonitrile as versatile amino sources in copper-catalyzed mild electrochemical $\mathrm{C}-\mathrm{H}$ amidation reactions $\dagger$}

\begin{abstract}
Sofia Strekalova, (D) *a Alexander Kononov, ${ }^{\text {ab }}$ Ildar Rizvanov a and Yulia Budnikova (DD *ab
A mild, efficient electrochemical approach to the site-selective direct $\mathrm{C}-\mathrm{H}$ amidation of benzene and its derivatives with acetonitrile and benzonitrile has been developed. It has been shown that joint electrochemical oxidation of various arenes in the presence of a copper salt as a catalyst and nitriles leads to the formation of $\mathrm{N}$-phenylacetamide from benzene and $\mathrm{N}$-benzylacetamides from benzyl derivatives (up to $78 \%$ yield). A favorable feature of the process is mild conditions (room temperature, ambient pressure, no strong oxidants) that meet the criteria of green chemistry.
\end{abstract}

Direct functionalization of $\mathrm{C}-\mathrm{H}$ bonds is one of the most popular tools in organic synthesis and allows formation of complex molecules from structurally simple starting substrates in one step. ${ }^{1}$ The direct functionalization of carbon-hydrogen bonds catalyzed by transition metals is currently one of the main ways of constructing carbon-element bonds (C-N, C-C, C-P, C- $\mathrm{R}_{\mathrm{f}}$ etc.). ${ }^{2}$ Catalysed by transition metals, $\mathrm{C}-\mathrm{N}$ bond building reactions are of particular importance in biology, pharmaceuticals and materials science. ${ }^{3}$ There are many examples of $\mathrm{C}-\mathrm{N}$ bond formation reactions using organic (pseudo) halides such as aryl iodides, bromides, chlorides, triflates and sulfonates, that react with amines or their precursors. Ullmann and Goldberg were the first to report on the $N$-arylation of aryl halides using a copper mediator, ${ }^{4}$ and later $\mathrm{Pd}, \mathrm{Cu}$ and $\mathrm{Rh}$ catalyzed $\mathrm{C}-\mathrm{N}$ bond formation with suitable ligands was developed (Scheme 1 , reaction 1 ). ${ }^{5}$

However, as a rule, such catalytic reactions have limited practical application due to the requirements for stoichiometric amounts of reagents and harsh reaction conditions (high temperature, high pressure, excess amount of strong oxidants, etc.). In addition these reactions involve strong chemical oxidants that are expensive, reduce the atomic economy of the process and lead to the formation of by-products. To address those limitations, reactions of $\mathrm{C}-\mathrm{H}$ functionalization catalysed by transition metals by means of electrochemical oxidation ${ }^{6}$ and photoelectrochemistry ${ }^{7}$ have been developed relatively recently.

Electrocatalytic approaches have been shown to be effective methods for building $\mathrm{C}-\mathrm{P}, \mathrm{C}-\mathrm{C}, \mathrm{C}-\mathrm{R}_{\mathrm{f}}$ and $\mathrm{C}-\mathrm{N}$ bonds. ${ }^{8}$ In particular, the synthesis of $N$-arylamides is of particular interest

${ }^{a}$ Arbuzov Institute of Organic and Physical Chemistry, FRC Kazan Scientific Center of RAS, Kazan, 420088 Russian Federation.E-mail: strekalova@iopc.ru; yulia@iopc.ru ${ }^{b}$ Kazan National Research Technological University, Kazan, 420015 Russian Federation

$\dagger$ Electronic supplementary information (ESI) available. See DOI: 10.1039/d1ra07650g for organic chemists, since amides are important structural frameworks presented in natural products, biological compounds, pharmaceuticals and synthetic materials. ${ }^{9}$ Therefore, the search for the new methods to synthesize $\mathrm{N}$-arylamides, including electrochemical approach, is of current interest. The synthesis of $N$-arylamides could be more accessible while using nitriles as amidation agents instead of amides.

It is known that certain alkanes can be oxidized at sufficiently high electrode potentials in acetonitrile with functionalization of $\mathrm{C}\left(\mathrm{sp}^{3}\right)-\mathrm{H}$ bonds. Koch and Miller studied the electrochemical acetamidation reaction of adamantanes in
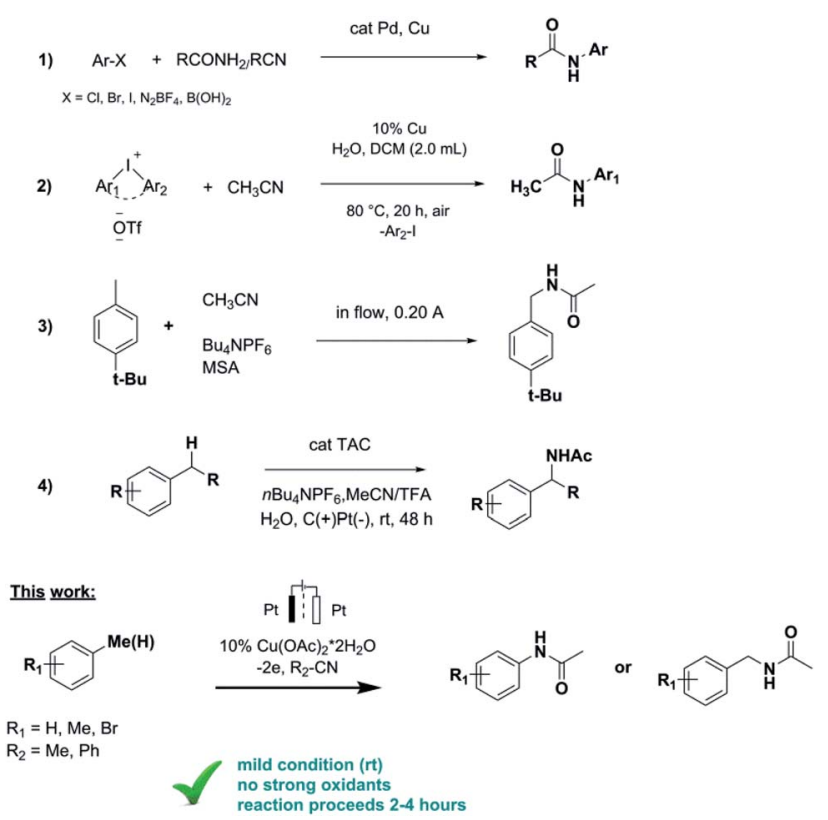

Scheme 1 Strategies for the synthesis of $N$-arylamides and $N$ benzylamides. 
acetonitrile at a platinum anode. ${ }^{\mathbf{1 0}}$ The anodic oxidation of adamantine was performed potentiostatically producing $\mathrm{N}$-(1adamanty1)acetonitrilium ions as the major product. Further aqueous work-up was leading to the formation of 1-adamantylacetamide in $65-90 \%$ yields.

Ji group developed an efficient and practical methodology for the synthesis of $\mathrm{N}$-arylamides via copper catalyzed amidation of diaryliodonium salts with nitriles (Scheme 1, reaction 2). ${ }^{11} \mathrm{~N}$ Arylated amides were obtained in moderate to good yields (up to $88 \%$ ) and various substituted aryl nitriles and aliphatic nitriles could be applied in this reaction.

Ley and coworkers reported on the preparation of benzyl amides from a number of aromatic hydrocarbons by a stable and continuous flow anodic oxidation using $\mathrm{Bu}_{4} \mathrm{NPF}_{6}$ as electrolyte and Brønsted acid additives (Scheme 1, reaction 3). ${ }^{\mathbf{1 2}}$ The amide derivatives of various para-, meta- and ortho-substituted benzene derivatives were obtained in good yields (64\%). However the continuous flow electrolysis could not be carried out in pure acetonitrile and limited to certain substrates.

In Vecchio group the series of acetamides was obtained in high yields under solvent- and catalyst-free conditions using isopropenyl acetate as reagent for acetylation of amines. ${ }^{13}$ Although this protocol is not suitable for unsubstituted arenes.

Just recently Shen and Lambert reported on electrophotocatalytic convert benzylic $\mathrm{C}-\mathrm{H}$ bonds to acetamides with the use of hard-to-find and expensive trisaminocyclopropenium (TAC) ion as catalyst (Scheme 1, reaction 4). ${ }^{\mathbf{1 4}}$ The protocol is compatible with many functional groups and was demonstrated on complex substrates although no examples of aromatic ring amidation reaction were provided.

Anodic oxidation of 1-(trifluoromethyl)benzene in dry acetonitrile $/ \mathrm{Bu}_{4} \mathrm{NBF}_{4}$ under constant potential conditions leading to 2-

Table 1 Electrocatalytic oxidation of benzene ${ }^{a}$

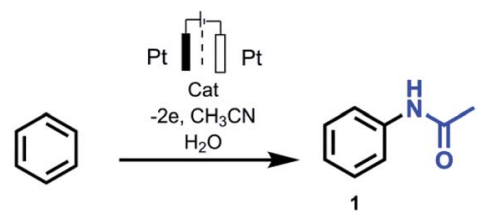

\begin{tabular}{lllll}
\hline No. & Catalyst & Additive & Solvent & Yield $^{b}$ \\
\hline 1 & $5 \%, \mathrm{Cu}(\mathrm{OAc})_{2}$ & - & MeCN & 54 \\
2 & $10 \%, \mathrm{Cu}(\mathrm{OAc})_{2}$ & - & MeCN & 70 \\
3 & - & - & MeCN & - \\
4 & 1 eq., $\mathrm{Cu}(\mathrm{OAc})_{2}$ & - & MeCN & 42 \\
$5^{c}$ & $10 \%, \mathrm{Cu}(\mathrm{OAc})_{2}$ & - & $\mathrm{DCM} / \mathrm{MeCN}$ & - \\
6 & $10 \%, \mathrm{Cu}(\mathrm{OAc})_{2}$ & $\mathrm{NH}_{2} \mathrm{COOMe}$ & $\mathrm{MeCN}$ & 61 \\
7 & $10 \%, \mathrm{Cu}(\mathrm{OAc})_{2}$ & $\mathrm{~K}_{3} \mathrm{PO}_{4}$ & $\mathrm{MeCN}$ & 30 \\
8 & $10 \%, \mathrm{Cu}(\mathrm{OAc})_{2}$ & $\mathrm{Et}_{3} \mathrm{~N}$ & $\mathrm{MeCN}$ & 23 \\
9 & $\mathrm{Co}(\mathrm{BF})_{2} \cdot 6 \mathrm{H}_{2} \mathrm{O}$ & - & $\mathrm{MeCN}$ & - \\
$10^{d}$ & $10 \%, \mathrm{Cu}(\mathrm{OAc})_{2}$ & - & $\mathrm{MeCN}$ & 21 \\
11 & $10 \%, \mathrm{Mn}(\mathrm{OAc})_{2}$ & - & $\mathrm{MeCN}$ & - \\
12 & $10 \%, \mathrm{Pd}(\mathrm{OAc})_{2}$ & - & $\mathrm{MeCN}$ & -
\end{tabular}

${ }^{a}$ Reaction conditions: benzene ( $\left.1 \mathrm{mmol}\right)$, catalyst $(0.1 \mathrm{mmol}, 10 \mathrm{~mol} \%)$, $\mathrm{H}_{2} \mathrm{O}(1 \mathrm{mmol})$, rt, divided cell, $2 \mathrm{~F}$ electricity $(80 \mathrm{~mA} \mathrm{~h}) .{ }^{b}$ Isolated. ${ }^{c}$ DCM : MeCN (40:1). ${ }^{d}$ Without $\mathrm{H}_{2} \mathrm{O}$. (trifluoromethyl) acetanilide was proposed by Barba et al. ${ }^{15}$ No other substrates were demonstrated in this protocol.

Inspired by the literature data in this area we report on the optimized conditions of the cross-coupling reaction between unsubstituted arenes (e.g. benzene) and different nitriles. Relying on the previously obtained experience of Cu-catalyzed electrochemical amination reactions, ${ }^{8 g}$ copper acetate salt was chosen as a catalyst. Thus, electrooxidation of benzene in MeCN in the presence of catalytic amount of copper acetate leaded to the formation of acetanilide as only product with a yield of $70 \%$ (Table 1). Acetanilide wasn't formed in the absence of copper acetate. $\mathrm{Mn}(\mathrm{OAc})_{2}$ and $\mathrm{Pd}(\mathrm{OAc})_{2}$ salts were also tested as catalysts for electrochemical $\mathrm{C}-\mathrm{H}$ amidation of benzene with nitriles but unsuccessfully under our conditions.

Aromatic ring Ritter reaction also proceeds when bromobenzene, $p$-dibromobenzene and trifluormethylbenzene are used as substrates (Scheme 2). In the case of using bromobenzene, $N$-(4-bromophenyl)acetamide (2b) is formed as a major isomer. This is most likely due to the steric factor of the bulky bromine substituent presence. While using trifluormethylbenzene as a substrate, the major product is $\mathrm{N}-(2$ (trifluoromethyl)phenyl)acetamide (4a) probably due to strong

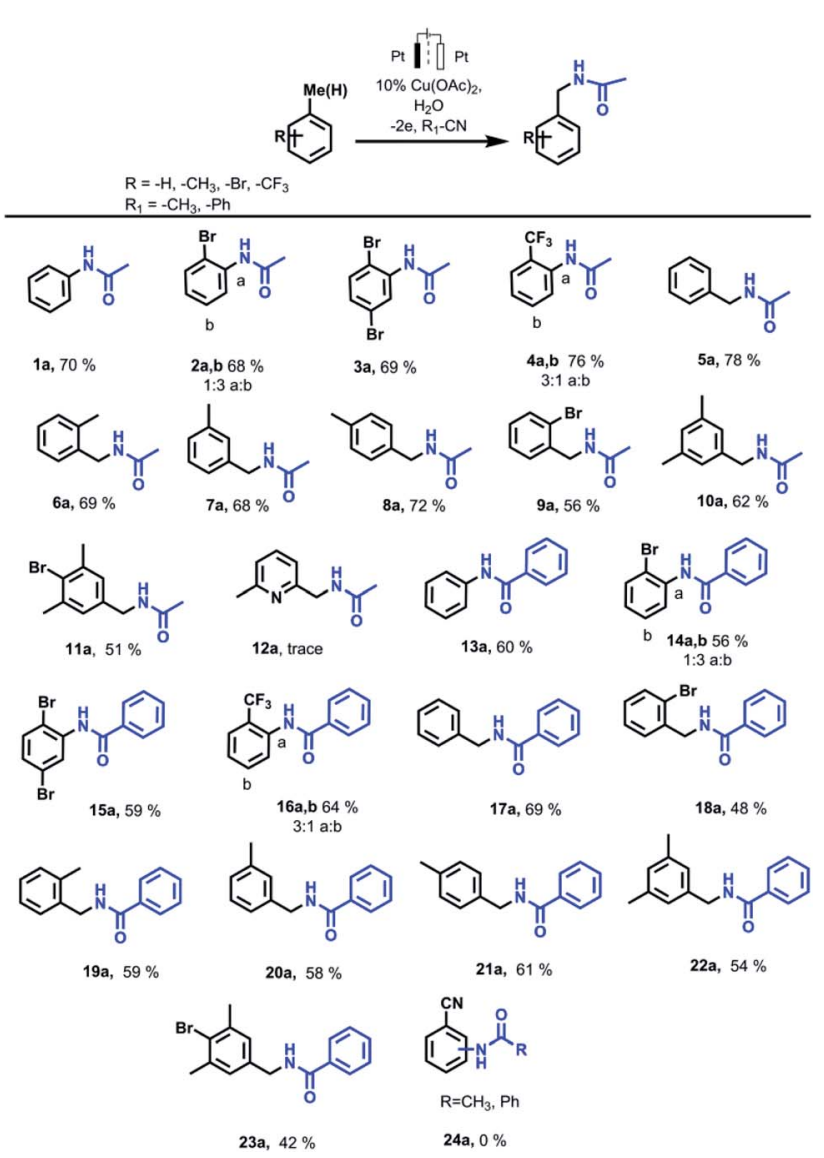

Scheme 2 Electrocatalytic amidation of benzene and benzyl derivatives. Reaction condition: substrate $(1 \mathrm{mmol}), \mathrm{Cu}(\mathrm{OAc})_{2}(0.1 \mathrm{mmol}$, $10 \mathrm{~mol} \%), \mathrm{H}_{2} \mathrm{O}(1 \mathrm{mmol}), \mathrm{MeCN}(40 \mathrm{~mL}), \mathrm{Pt}-\mathrm{Pt}$, divided cell, constant current, isolated yield. 
inductive effect of the trifluoromethyl group what makes the adjacent positions assailable to nucleophilic attack.

In the presence of copper salt, further reactions were carried out with methyl-substituted arenes such as toluene, xylenes, 2bromtoluene, mesitylene, 2-bromomesitylene, etc. The results obtained from the electrocatalytic oxidation of arenes in $\mathrm{R}-\mathrm{CN}$ (MeCN, PhCN) are summarized in Scheme 2. In case of a methyl group presents in the aromatic ring of a substrate, the reaction proceeds with the participation of a methyl fragment. When substrates have several methyl groups (xylene, mesitylene), amidation products with one substituted methyl group are obtained as the main product even while passing more electricity $(4 \mathrm{~F})$.

Molecular weight of the amidation products were verified via GC-MS analysis. According to GC-MS data amidation product with three acetamide fragments is also formed when 2-bromomesitylene is used as a substrate. The presence of bromine substituent in the aromatic ring probably affects the reactivity so the yield of the main product decreases due to the formation of dimers that are also observed via GC-MS analysis. In case of using $o$-bromotoluene as a substrate we also registered the formation of a small amount of $o$-bromobenzaldehyde as a byproduct that wasn't observed while using other substrates. In case of 2,6-dimethyllutidine, only a trace amount of the desired product is observed. This is probably due to the coordination properties of 2,6-dimethyllutidine itself and the formation of a copper complex.

When naphthalene, 2,6-dimethylnaphthalene, 2-phenylpyridine, $p$-bromoanisole and anisole were tested in electrooxidation reaction, formation of the $\mathrm{C}-\mathrm{C}$ bond (dimer formation) was observed instead of the expected $\mathrm{C}-\mathrm{N}$ bond (Scheme 3) according to GC-MS data. Passing $2 \mathrm{~F}$ is sufficient to form dimers of anisole, $p$-bromoanisole and phenylpyridine. In the case of $p$-bromoanisole and anisole, di-, tri-, and tetradimers are formed. Conversion of naphthalene reaches $90 \%$ after passing $4 \mathrm{~F}$ electricity, in this case 2,2'-binaphthyl is formed. When using coumarin, 7-methylcoumarin, benzonitrile and caffeine the products of cross-coupling with $\mathrm{CH}_{3} \mathrm{CN}$ or dimers were not formed.

On the basis of the preparative electrolysis and cyclic voltammetry data and the previous studies on anodic oxidation of investigated molecules, ${ }^{8 g, 16}$ the general scheme of possible $\mathrm{C}-\mathrm{H}$ transformations depending on the substrate nature (aromatic or

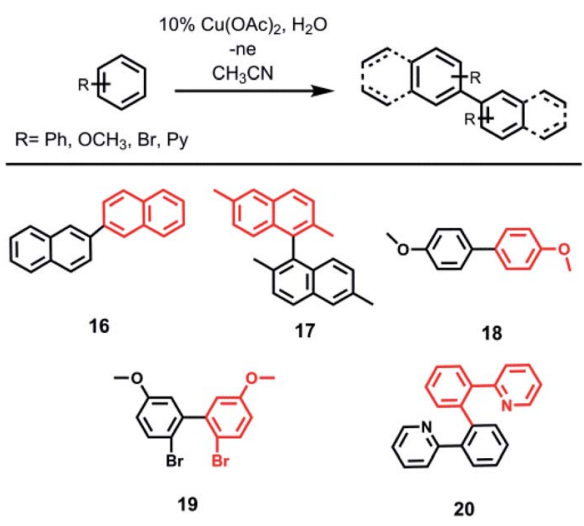

Scheme 3 Electrocatalytic homo-cross-coupling of aromatics.

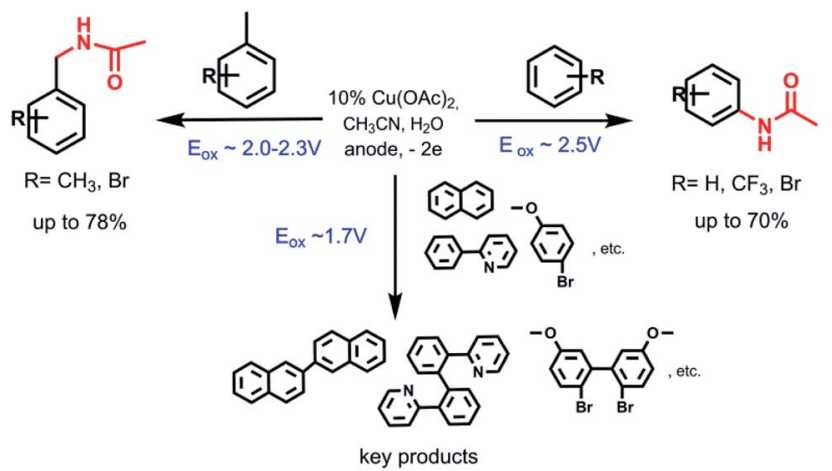

Scheme 4 Different ways of $\mathrm{C}-\mathrm{H}$ transformation depending on the substrate nature and oxidation potentials.

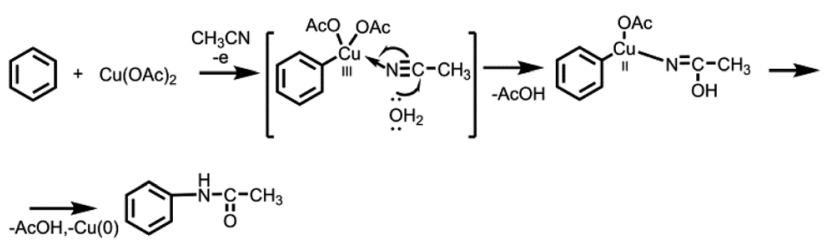

Scheme 5 Plausible mechanism for the amidation of benzene.

heteroaromatic, presence of substituents) and oxidation potentials of using substrates can be represented as follows Scheme 4 .

It is obvious that the one of the criteria of success and selectivity of the amidation reaction, either an aromatic $\mathrm{C}-\left(\mathrm{sp}^{2}\right)-\mathrm{H}$ or a benzyl $\mathrm{C}-\left(\mathrm{sp}^{3}\right)-\mathrm{H}$ bond, is determined by the electrolysis potential, namely, by the oxidation potentials of the reaction participants (Table S2 $\dagger$ ). Amidation of the aromatic ring occurs only in the case of difficult oxidizable substrates (benzene, bromobenzene, $p$ dibromobenzene, trifluormethylbenzene) according to the following possible scheme (Scheme 5):

The presence of a methyl substituent on the benzene ring leads to selective amidation of the benzyl fragment and the reaction is already proceeding through the oxidation of methyl group. However, no radical intermediates were detected by EPR. Heteroarenes (e.g. 2-phenylpyridine) have the ability to coordinate with metals; thus, during electrooxidation of heteroarenes the dimers are formed instead of acetylamides.

Thus, depending on the substrate nature (aromatic or heteroaromatic, presence of methyl or other substituents) and the oxidation potentials of aromatics, the reaction proceeds in different way under the same conditions.

\section{Conclusions}

The electrochemical oxidation of benzene and its derivatives catalyzed by copper acetate leads to the formation of $\mathrm{N}$-amides in the presence of acetonitrile and benzonitrile. Traditionally inert widely used in electrochemical studies MeCN and PhCN are shown to be an amidation agent for electrochemical Cu-catalyzed siteselective aromatic $\mathrm{C}-\mathrm{H}$ substitution. The reaction products are obtained with good yield (up to 78\%) in one step during 2 hours under electrochemical mild conditions (room temperature, 
ambient pressure, without strong oxidants). The results provided here open up to the application of more complex substrates to build amine or amide $\mathrm{C}-\mathrm{N}$ bonds.

\section{Conflicts of interest}

There are no conflicts to declare.

\section{Acknowledgements}

The authors gratefully acknowledge the partial financial support from the government assignment for FRC Kazan Scientific Center of RAS for voltammetry and NMR investigations. The electrosynthesis was supported by the Russian Science Foundation, grant No. 19-13-00016. AK and YB performed mass spectrometric studies in Kazan National Research Technological University.

\section{Notes and references}

1 (a) T. Gensch, M. N. Hopkinson, F. Glorius and J. WencelDelord, Chem. Soc. Rev., 2016, 45, 2900; (b) Y. N. Aher and A. B. Pawar, Chem. Commun., 2021, 57, 7164; (c) F. Roudesly, J. Oble and G. Poli, J. Mol. Catal. A: Chem., 2017, 426, 275; (d) H. Yi, G. Zhang, H. Wang, Z. Huang, J. Wang, A. K. Singh and A. Lei, Chem. Rev., 2017, 117, 9016; (e) M. D. Kärkäs, Chem. Soc. Rev., 2018, 47, 5786; (f) D. S. Kopchuk, O. S. Taniya, A. F. Khasanov, A. P. Krinochkin, I. S. Kovalev, T. A. Pospelova, G. V. Zyryanov, V. L. Rusinov and O. N. Chupakhin, Chem. Heterocycl. Compd, 2019, 55, 490; $(g)$ Y. Yu, H. Lv and S. Li, Org. Biomol. Chem., 2020, 18, 8810.

2 (a) W. R. Gutekunst and P. S. Baran, Chem. Soc. Rev., 2011, 40, 1976; (b) Y. Kommagalla and N. Chatani, Coord. Chem. Rev., 2017, 350, 117; (c) F. Monnier and M. Taillefer, Angew. Chem., Int. Ed., 2009, 48, 6954; (d) T. Aneeja, M. Neetha, C. M. A. Afsina and G. Anilkumar, RSC Adv., 2020, 10, 34429; (e) X. Tang, W. Wu, W. Zeng and H. Jiang, Acc. Chem. Res., 2018, 51, 1092; (f) S. K. Banjare, T. Nanda, B. V. Pati, P. Biswal and P. C. Ravikumar, Chem. Commun., 2021, 57, 3630.

3 (a) R. Hili and A. K. Yudin, Nat. Chem. Biol., 2006, 2, 284; (b) Amino Group Chemistry: From Synthesis to the Life Sciences, ed. A. Ricci, Wiley-VCH, Weinheim, 2007, Amino group chemistry: from synthesis to the life sciences, ed. A. Ricci, John Wiley \& Sons, 2008.

4 (a) I. Goldberg, Ber. Dtsch. Chem. Ges., 1906, 39, 1691; (b) F. Ullmann, Ber. Dtsch. Chem. Ges., 1903, 36, 2382.

5 (a) R. Dorel, C. P. Grugel and A. M. Haydl, Angew. Chem., Int. $E d .$, 2019, 58, 17118; (b) F. Meng, C. Wang, J. Xie, X. Zhu and Y. Wan, Appl. Organomet. Chem., 2011, 25, 341; (c) Q. Gu and E. Vessally, RSC Adv., 2020, 10, 16756; (d) M. J. West, J. W. Fyfe, J. C. Vantourout and A. J. Watson, Chem. Rev., 2019, 119, 12491.

6 (a) C. Ma, P. Fang and T. S. Mei, ACS Catal., 2018, 8, 7179; (b) Y. Kawamata, M. Yan, Z. Liu, D. H. Bao, J. Chen, J. T. Starr and P. S. Baran, J. Am. Chem. Soc., 2017, 139, 7448; (c) J. H. Wang, T. Lei, X. L. Nan, H. L. Wu, X. B. Li, B. Chen,
C. H. Tung and L. Z. Wu, Org. Lett., 2019, 21, 5581; (d) S. Kathiravan, S. Suriyanarayanan and I. A. Nicholls, Org. Lett., 2019, 21, 1968; (e) N. Sauermann, T. H. Meyer, Y. Qiu and L. Ackermann, ACS Catal., 2018, 8, 7086; (f) J. Chen, S. Lv and S. Tian, ChemSusChem, 2019, 12, 115.

7 (a) L. Zhang, L. Liardet, J. Luo, D. Ren, M. Grätzel and X. Hu, Nat. Catal., 2019, 2, 366; (b) Y. Zhao and W. Xia, Chem. Soc. Rev., 2018, 47, 2591; (c) J. P. Barham and B. König, Angew. Chem., Int. Ed., 2020, 59, 11732; (d) K. Rajeshwar, M. K. Hossain, R. T. Macaluso, C. Janáky, A. Varga and P. J. Kulesza, J. Electrochem. Soc., 2018, 165, H3192; (e) P. Wang, X. Ma, M. Su, Q. Hao, J. Lei and H. Ju, Chem. Commun., 2012, 48, 10216; (f) V. Dwivedi, D. Kalsi and B. Sundararaju, ChemCatChem, 2019, 11, 5160.

8 (a) A. Wiebe, T. Gieshoff, S. Möhle, E. Rodrigo, M. Zirbes and S. R. Waldvogel, Angew. Chem., Int. Ed., 2018, 57, 5594; (b) S. Strekalova, M. Khrizanforov and Y. Budnikova, Molecules, 2019, 24, 1823; (c) M. Khrizanforov, S. Strekalova, V. Khrizanforova, A. Dobrynin, K. Kholin, T. Gryaznova, V. Grinenko, A. Gubaidullin, M. K. Kadirov and Y. Budnikova, Top. Catal., 2018, 61, 1949; (d) M. N. Khrizanforov, S. V. Fedorenko, A. R. Mustafina, K. V. Kholin, I. R. Nizameev, S. O. Strekalova, V. V. Grinenko, T. V. Gryaznova, R. R. Zairov, R. Mazzaro, V. Morandi, A. Vomiero and Y. H. Budnikova, Dalton Trans., 2018, 47, 9608; (e) M. N. Khrizanforov, S. O. Strekalova, K. V. Kholin, V. V. Khrizanforova, M. K. Kadirov, T. V. Gryaznova and Y. H. Budnikova, Catal. Today, 2017, 279, 133; (f) Y. H. Budnikova, O. Bochkova, M. Khrizanforov, I. Nizameev, K. Kholin, T. Gryaznova, A. Laskin, Y. Dudkina, S. Strekalova, S. Fedorenko, A. Kononov and A. Mustafina, ChemCatChem, 2019, 11, 5615; $(g)$ T. V. Gryaznova, K. V. Kholin, E. O. Nikanshina, V. V. Khrizanforova, S. O. Strekalova, R. R. Fayzullin and Y. H. Budnikova, Organometallics, 2019, 38, 3617; (h) S. D. Minteer and P. Baran, Acc. Chem. Res., 2020, 53, 545.

9 (a) R. García-Álvarez, P. Crochet and V. Cadierno, Green Chem., 2013, 15, 46; (b) I. P. Beletskaya, Pure Appl. Chem., 2005, 77, 2021; (c) F. Monnier and M. Taillefer, Angew. Chem., Int. Ed., 2009, 48, 6954; (d) M. A. Mintzer and E. E. Simanek, Chem. Rev., 2009, 109, 259; (e) X. Wang, J. Liu and G. An, Tetrahedron Lett., 2020, 61, 152327.

10 V. R. Koch and L. L. Miller, J. Am. Chem. Soc., 1973, 95, 8631. 11 H. C. Cheng, L. Zhou, X. Zhou, J. L. Ma, P. Guo, Y. Zhang and H. B. Ji, Tetrahedron Lett., 2021, 71, 153048.

12 M. A. Kabeshov, B. Musio and S. V. Ley, React. Chem. Eng., 2017, 2, 822.

13 R. Pelagalli, I. Chiarotto, M. Feroci and S. Vecchio, Green Chem., 2012, 14, 2251.

14 T. Shen and T. H. Lambert, J. Am. Chem. Soc., 2021, 143, 8597.

15 F. Barba, I. Barba and B. Batanero, Electrochem. Commun., 2014, 48, 115.

16 Y. N. Toikka, A. S. Mikherdov, D. M. Ivanov, T. J. Mooibroek, N. A. Bokach and V. Y. Kukushkin, Cryst. Growth Des., 2020, 20, 4783-4793. 